Syntax Idea: p-ISSN: 2684-6853 e-ISSN: 2684-883X

Vol. 4, No. 1, Januari 2022

\title{
PERAN MASYARAKAT DALAM MENGEMBANGKAN CULTURAL EVENT
}

\author{
Ahmad Kurniawan, Elly Malihah, Rini Andari \\ Universitas Pendidikan Indonesia (UPI) Bandung Jawa Barat, Indonesia \\ Email: ahmadkurniawan015@upi.edu, ellymalihah@upi.edu, riniandari@upi.edu
}

\begin{abstract}
Abstrak
Melihat banyaknya masyarakat yang kurang peduli terhadap perkembangan dunia acara khususnya pada cultural event, sehingga menarik peneliti untuk mengkaji penelitian ini. Padahal sebenarnya peran masyarakat menjadi salah satu nilai penting dalam pembangunan pariwisata. Dikarenakan dengan adanya peran tersebut menjadikan masyarakat akan sadar dengan keuntungan yang didapat, sehingga dengan itu dapat memajukan daerah yang ditempatinya. Tujuan dalam penelitian ini tertuang dalam beberapa pertanyaan diantaranya apa peran masyarakat sebagai pelaksana pada cultural event? apa peran masyarakat sebagai penyerta pada cultural event?, kemudian apa peran masyarakat sebagai penerima manfaat pada cultural event? Melalui pendekatan penelitian berbasis kualitatif deskriptif dengan menggunakan metode wawancara, studi kepustakaan, dan catatan lapangan menghasilkan sebuah penelitian yang bertajuk pariwisata ini menjadi lebih cocok dan sejalan dengan dunia acara saat ini. Sehingga, dalam studi Yogja International Batik Biennale ini menarik peneliti untuk mengkaji pentingnya sebuah peran masyarakat dalam community based tourism untuk mengembangkan cultural event di Yogyakarta.
\end{abstract}

Kata Kunci: Peran masyarakat; cultural event; pariwisata; community based tourism; metode penelitian

\section{Abstract}

Seeing the number of people who are less concerned about the development of world events, especially cultural events, it is interesting for researchers to study this research. In fact, the role of the community is one of the important values in tourism development. Due to the existence of this role, the community will benefit, so that they can advance the area they occupy. The purpose of this research is stated in several questions including what is the role of the community as implementers at cultural events?, what is the role as participants in cultural events?, then what is the role of the community as beneficiaries of cultural events?. Through a descriptive qualitative-based approach using interviews, literature studies, and field notes, it produces a promotion that is suitable for this research with the current world of events. Thus, in this study, the Yogja International Batik Biennale attracted researchers to assess the importance of a community role in community-based tourism to develop cultural events in Yogyakarta.

Keywords: The role of society; cultural events; tourist; community based tourism; research methods

$\begin{array}{ll}\text { How to cite: } & \text { Kurniawan, A., Malihah, E., Andari, R., (2022) Peran Masyarakat dalam Mengembangkan Cultural Event, } \\ & \text { Syntax Idea, 4(1), https://doi.org/ 10.36418/syntax-idea.v 4i1.1752 } \\ \text { E-ISSN: } & \text { 2684-883X } \\ \text { Published by: } & \text { Ridwan Institute }\end{array}$




\section{Received: 2021-12-22; Accepted: 2022-01-05; Published: 2022-01-20}

\section{Pendahuluan}

Peran dimaksudkan sebagai konsep mengenai apa yang perlu dilakukan individu di dalam masyarakat (Wulansari, 2009). Senada dengan penyataan tersebut, (Link et al., 1993) menjelaskan peran sebagai perilaku yang diharapkan dari seseorang yang mempunyai status. Dari pemahaman sebelumnya, peran hakekatnya merupakan tindakan seseorang yang dilakukan dengan mengaitkan kedudukannya dalam suatu struktur sosial.

Apabila dikaitkan dengan masyarakat, maka peran masyarakat memiliki arti sebuah perlakuan yang dimainkan oleh sekelompok orang yang mencerminkan kesamaan perilaku entitas komunal yang berkaitan dengan struktur sosial tertentu. Dengan begitu peran masyarakat dapat dijelaskan dalam tiga sifat yakni adanya pembagian tugas masing-masing anggota kelompok, adanya kemiripan fungsi dari kelompok yang ditimbulkan dari pola pikir dan pola tindak, serta adanya kedudukan kelompok yang melakukan aktivitas secara bebarengan dalam suatu komuniti (Wudianto, Arnaya, Natsir, \& Herdiana, 2017).

Pemahaman peran masyarakat tersebut dalam konteks pengembangan cultural event atau acara kebudayaan dimaksudkan sebagai tindakan yang dilakukan masyarakat sekitar dalam menjaga dan melestarikan adat, tradisi serta budayanya yang ditampilkan dengan perhelatan cultural event. Dengan adanya perhelatan tersebut, suatu komuniti dapat terus mengembangkan kekayaan tradisional yang dimiliki untuk ditunjukkan pada kancah nasional maupun internasional. Penyelenggaraan cultural event saat ini dijadikan main event pada acara tahunan disetiap Provinsi di Indonesia, sebab kegiatan tersebut banyak mengundang wisatawan baik dari domestik maupun mancanegara yang tentunya berdampak pada peningkatan ekonomi yang signifikan didaerah tersebut.

Keunikan cultural event dapat memanjakan mata para pengunjung yang melihat langsung attraction pada kegiatan tersebut, mulai dari penampilan musik, seni, pagelaran, drama tradisi, hingga pada kerajinan lokal setempat (Dean, Novianti, \& Noor, 2020). Seperti halnya pada acara YIBB (Yogja Internasional Batik Biennale) yang selalu diadakan setiap dua tahun sekali di Kabupaten Bantul Provinsi DIY (Daerah Istimewa Yogyakarta). Kegiatan ini diinsiasi langsung oleh Pemerintah Kota Yogyakarta dengan tujuan mengingatkan sekaligus memamerkan warisan akan kentalnya budaya leluhur nenek moyang DIY terdahulu, sehingga khususnya masyarakat sekitar dapat menjadikan acara ini sebagai ajang penggalian sejarah masa lalu. Dikarenakan dengan datangnya globalisasi yang tidak dapat dihindari membuat masyarakat Yogja lupa akan jati diri budayanya. Maka dengan diadakannya acara inilah menjawab persoalan yang selama ini tergerus oleh zaman (Any Noor, 2017).

Selain mengenalkan budaya, acara Yogja International Batik Biennale juga diorientasikan untuk menunjukkan kearifan lokal tradisinya yang mayoritas masyarakatnya sebagai pengrajin batik, baik batik yang berupa cap maupun tulis yang tertuang dalam motif- motifnya. Berbagai motif batik asli Yogjayakarta seperti motif 
semen, motif parang rusak barong, motif ceplok kasatrian, motif kawung, motif ninik dan masih banyak motif-motif lainnya dikenalkan didalam suatu cultural event melalui penampilan pagelaran dan pameran. Acara ini pun tentunya didukung banyak pihak, terutama Sultan Yogyakarta. Alasannya pertama karena acara ini dapat dirasakan langsung dan berdampak positif bagi masyarakat Yogja sendiri, kedua agar masyarakat sadar bahwa tradisi perlu diingat dan dilestarikan, ketiga kalau bukan peran masyarakat yang menjaganya lantas siapa lagi.

Maka dari penjabaran diatas, membuat peneliti tertarik mengkaji topik ini, karena terlihat dengan banyaknya budaya yang tergerus oleh teknologi yang melupakan habitual tradition disetiap individu-individu khususnya masyarakat Daerah Istimewa Yogyakarta yang semakin terkikis oleh pengaruh kebarat-baratan. Tentu studi kasus ini memberikan pembelajaran kepada peneliti bahwa pentingnya peran masyarakat dalam mengembangkan cultural event.

Tujuan dalam penelitian ini dirumuskan dalam beberapa pertanyaan diantaranya apa peran masyarakat sebagai pelaksana pada cultural event?, apa peran masyarakat sebagai penyerta pada cultural event?, kemudian apa peran masyarakat sebagai penerima manfaat pada cultural event?. Sehingga dari tujuan penelitian sebelumnya tersebut memberikan manfaat yang berguna untuk pengembangan penelitian di bidang pariwisata terkait dengan community based tourism dalam lingkup cultural event.

\section{Metode Penelitian}

Secara keseluruhan, penelitian ini ialah penelitian yang menggunakan data kualitatif deskriptif. Hal ini dimaksudkan sebagai usaha mengumpulkan dan menyusun data yang kemudiakan dideskripsikan kedalam bentuk tulisan bukan termasuk angkaangka (Surakhmad, 1982). Memakai tiga metode pendukung yakni pertama dengan pendekatan studi wawancara mendalam kepada 3 (tiga) narasumber diantaranya Wakil Ketua Pokdarwis (kelompok sadar wisata) Kab. Bantul Yogyakarta, Pengelola Kampung Batik Giriloyo Bantul, dan salah satu masyarakat yang selalu berperan dalam suksesnya acara Yogja Internasional Batik Biennale. Kegiatan wawancara ini dilakukan selama satu hari dengan durasi satu jam per narasumber yang bertempatan langsung di Kampung Batik Giriloyo Kabupaten Bantul Provinsi Yogyakarta.

Adapun pertanyaan yang diajukan diantaranya apa peran masyarakat sebagai pelaksana pada cultural event? apa peran masyarakat sebagai penyerta pada cultural event?, kemudian apa peran masyarakat sebagai penerima manfaat pada cultural event?. Dimana keseluruhan pertanyaan ditujukan pada acara Yogja Internasional Batik Biennale.

Kedua, penelitian ini juga menggunakan pendekatan studi kepustakaan. Sebagaimana dijelaskan oleh (Zed, 2004) bahwa studi kepustakaan ialah penelitian yang memanfaat sumber kepustakaan guna memperoleh data tambahan penelitian, sehingga dalam penelitian ini referensi kepustakaan menjadi sumber kedua tambahan peneliti dalam meneliti topik ini. Studi kepustakaan yang dimaksud adalah mencari dan mempelajari berbagai literatur yang ada seperti buku-buku, jurnal ilmiah, artikel 
kepariwisataan, artikel populer event, artikel community based tourism yang berkaitan dengan peran masyarakat dalam pengembangan cultural event.

Ketiga, dengan menggunakan catatan lapangan yang ikut menjadi sumber tambahan data dalam penelitian ini, sebab jika hanya mengandalkan wawancara dan studi kepustakaan saja akan kurang dalam kajiannya. Maka ditambahlah dengan menggunakan catatan lapangan agar interepretasi yang dicantumkan dapat sesuai dengan perkembangan yang ada. Ditambah lagi dengan adanya sebuah pengalaman peneliti sebelumnya terkait dengan topik bisa menambah wawasan dalam penelitian.

\section{Hasil dan Pembahasan}

\section{Peran masyarakat sebagai pelaksana pada cultural event}

Dalam hal ini masyarakat menjadi pihak yang menginisiasi pelaksanaan cultural event pada kegiatan YIBB. Pada pelaksanaannya masyarakat setuju dengan adanya program yang dicetuskan oleh Pemerintah Kota Bantul sebelumnya. Bermula karena adanya dampak gempa bumi besar-besaran di Yogyakarta yang terjadi pada tahun 2006, dimana pada saat itu seluruh rakyat Indonesia khawatir akan keselamatan masyarakat yang berada di sekitar Gunung tersebut. Termasuk penduduk sekitar Bantul yang tertimpa musibah membuat semua kebutuhan hidupnya serba kekurangan. Terlebih lagi keadaan ekonomi yang semakin mencekik saat itu. Namun dari bencana itu tidak membuat masyarakat Bantul patah semangat, dengan ujian ini menjadikan masyarakat sekitar bangkit kembali memikirkan keadaan ekonominya agar bisa bangkit lagi. Terbukti terlihat dari bekas rumah warga yang dijadikan sebagai bukti dahsyatnya gempa yang mengguncang kawasan

Bantul.Dari segi semangatnya masyarakat pun tergambar dengan mulainya mencari-cari kegiatan yang bisa mengkreasikan sesuatu agar bisa bernilai uang, agar kebutuhan hidupnya dapat tercukupi. Melihat adanya banyak potensi dalam membatik yang pernah dilakukan nenek moyangnya sejak dulu, membuat masyarakat ingat untuk melestarikan lagi kebiasaan membatik tersebut. Bermodalkan kain mori dan cat batik asli Bantul yang terbuat dari kulit kayu tingi, soga, tegeran menciptakan suatu batik tulis yang halus. Dengan pengerjaan selama kurang lebih tiga bulan perkain batik, tidak memudarkan semangat masyarakat untuk berkarya.

Setelah lama kemudian batik tulis ini banyak dilirik oleh penggemar batik tradisional Indonesia, sehingga kegiatan promosipun dimana-mana. Ditambah lagi dengan adanya pernyataan yang dikeluarkan oleh Presiden Republik Indonesia bahwa batik merupakan khas kekayaan Indonesia, sehingga menjadikan batik Bantul laris diberbagai pasaran. Melihat banyaknya potensi keuntungan yang bisa diraup dari batik ini, masyarakat memberikan saran kepada Pemerintah setempat untuk diadakannya sebuah perhelatan cultural event yang bertajuk pariwisata ini agar dapat mengenalkan dan bisa melestarikan kekayaan tradisionalnnya khususnya kegiatan membatik di Bantul dan daerah-daerah lain di Yogyakarta sebagai penghasil batik.

Kekhawatiran yang dirasakan oleh masyarakat sekitar akan lunturnya warisan budaya yang telah diberikan nenek moyang tidak bisa diteruskan oleh generasi 
selanjutnya. Maka dengan itulah masyakat dengan persetujuan dari pemerintah setempat membuat acara Yogja Internasional Batik Bienalle. Dengan acara yang bernuansa cultural event ini dapat dikembangkan melalui pagelaran seni, musik dan lain sebagainya yang dikemas dalam satu kegiatan.

\section{Peran masyarakat sebagai penyerta pada cultural event}

Berkembangnya pariwisata saat ini memberikan semangat kepada masyarakat sebagai penyerta atau partisipasi untuk memajukan sektor pariwisatanya melalui pengadaan cultural event. Partisipasi masyarakat dalam hal pengembangan event di Yogyakarta memposisikan cultural event sebagai annual event yang dibanggakan dan ditunggu-tunggu setiap dua tahun sekali diselenggarakan. Hal tersebut menjadikan nilai lebih bagi masyarakat untuk terus ikut andil dalam mendapatkan informasi terkait kebutuhan, kondisi, serta sikap masyarakat terhadap cultural event. Tanpa adanya partisipasi masyarakat program pembangunan dan proyek-proyek tidak akan berhasil, sebab rakyat akan lebih percaya terhadap program yang dikembangkan jika masyarakatnya merasa dilibatkan dalam proses perencanaan dan persiapannya (Doganer et al., 2015).

Dalam konteks pengembangan cultural event di Yogyakarta, banyak masyarakat yang melibatkan diri untuk ikut dalam prosesnya karena mereka tahu bahwa dengan perannya setiap kegiatan yang didirikan dapat menjadi pemersatu diantara kelompok masyarakat yang lain. Mendorong adanya partisipasi masyarakat yang sifatnya umum dalam pembangunan daerah ditimbulkan dari pemikiran demokrasi masyarakat atas keterlibatan mereka untuk memajukan kawasannya. Pengelolaan kawasan yang dijadikan sebagai tempat pengadaan cultural event pada acara Yogja International Batik Bienalle sudah menerapkan konsep perencanaan, pelaksanaan monitoring, dan evaluasi yang semuanya melibatkan peran masyarakat setempat.

Dengan begitu istilah yang mengatakan masyarakat sebagai komponen utama adalah benar adanya. Karena pembangunan pariwisata yang berbasis masyarakat atau community based tourism ditujukan guna pengembangan potensi lokal yang bersumber dari alam dan sosial budaya telah diterapkan dengan baik pada cultural event ini. Pengembangan cultural event dalam perspektif kemandirian lokal di Yogja merupakan perwujudan interkoneksitas dalam tatanan masyarakat yang dilakukan secara mandiri agar dapat terus meningkatkan kualitas tatanan dengan tetap memelihara kelestarian alam, nilai-nilai budaya lokal dan obyek wisata budaya yang ada dengan ditampilkan pada acara Yogja International Batik Biennale.

\section{Peran masyarakat sebagai penerima manfaat pada cultural event}

Pada dasarnya penyelenggaraan cultural event kerap kali menjadi kegiatan yang menguntungkan ekonomi bagi masyarakat setempat. Seperti halnya masyarakat yang berada didaerah Yogja terutama di Bantul, mereka mengakui bahwa dengan adanya cultural event ini secara tidak langsung dapat membantu meningkatkan 
perekonomian mereka selama acara berlangsung. Karena melalui acara ini mereka dapat menjual produk khas lokal Yogyakarta berupa pakaian adatnya, kuliner, serta produk bermacam souvenir bisa habis hingga acara selesai. Maka dari situlah mereka mengasumsikan bahwa dengan diselenggarakannya cultural event ini adanya kebermanfaatan yang sangat luar biasa yang mereka peroleh.

Bukan hanya itu saja, masyarakat Yogja pun merasa terkagum-kagum dengan ditampilkannya kesenian-kesenian yang nenek moyang mereka lakukan dahulu. Dengan begitu mereka pun ingat dan ikut menyukseskan kegiatan yang penuh dengan manfaat ini. Berawal dari rasa bangga tersebut masyarakat telah terbuka dengan wisatawan luar untuk mengenalkan dan menunjukkan budaya mereka kepada pengunjung yang datang. Wisatawan yang melihat pun ikut menyaksikan pertunjukkan dari masyarakat lokal akan tradisinya. Kebermanfaatan pun dirasakan juga oleh pimpinan daerah setempat bahwa menariknya budaya kesultanan Daerah Istimewa Yogyakarta jika terus dikembangkan melalui kontes penyelenggaraan Yogja International Batik Biennale ini.

Maka tak diragukan lagi apabila cultural event dijadikan sebagai kegiatan yang banyak mendatangkan keuntungan dan manfaat bagi masyarakat yang berada disekitar tempat penyelenggaraan acara. Menariknya dengan diadakannya acara ini adalah batik lokal masyarakat Yogja dalam motif apapun telah dikenal oleh negaranegara tetangga Indonesia yang diundang pada saat penyelenggaraan cultural event ini.

\section{Kesimpulan}

Kontribusi masyarakat sangat berperan dalam mengembangkan cultural event. Berangkat dari harapan-harapan masyarakat untuk meningkatkan pendapatan ekonominya ialah nafas lega bagi sebagian masyarakat yang dapat ikut serta bekerja didalamnya. Bentuk peran masyarakat dalam hal community based tourism menjadi tolak ukur bagi suatu komuniti untuk terus mengembangkan sektor pariwisata khususnya pada ranah cultural event, sebab kalau bukan masyarakat Yogjakarta sendiri yang bisa menjaganya lalu siapa lagi. Penyelenggaraan cultural event dalam studi Yogja International Batik Bienale ini telah menjadi bagian penting dalam pembangkit dunia acara di Yokyakarta. Melalui pertunjukan seninya, budayanya, tradisinya, produk lokalnya, dan lain sebagainya selalu memberikan manfaat yang signifikan yang dirasakan langsung oleh masyarakat.

Untuk peneliti selanjutnya, topik ini bisa terus dikembangkan dalam dunia event. Dikarenakan masih sedikit akademisi-akademisi maupun masyarakat diluar sana yang belum memahami esensi dari sebuah penyelenggaraan cultural event, sehingga perlu adanya kajian- kajian yang lebih luas terkait dengan hal ini. 


\section{BIBLIOGRAFI}

Andy. (2018). Partisipasi Masyarakat dalam Pengembangan Wisata Budaya . Jurnal Sosial Budaya.

Baro, X. (2015). ChaLearn Looking at People 2015 Challenges: Action Spotting and Cultural Event Recognition. Proceedings of the IEEE Conference on Computer Vision and Pattern Recognition (CVPR) Workshops. Google Scholar

Dodds, R. (2018). Mobilizing knowledge: determining key elements for success and pitfalls in developing community-based tourism. Current Issues in Tourism. Google Scholar

Dangi, T.B. (2016). An Integrated Approach to "Sustainable Community-Based Tourism”. MDPI Journal. Google Scholar

Dean, David, Novianti, Syifaa, \& Noor, Any Ariani. (2020). An assessment of the international and domestic tourists behavior in Australia. International Journal of Applied Business Research, 2(01), 46-57.Google Scholar

Escalera, S. (2015). ChaLearn Looking at People 2015: Apparent Age and Cultural Event Recognition Datasets and Results. Proceedings of the IEEE International Conference on Computer Vision (ICCV) Workshops. Google Scholar

Giampiccoli, A. (2016). Towards a comprehensive model of community-based tourism development. Sabinet African Journal. Google Scholar

Hanya Pielichaty, Georgiana Els, Ian Reed and Vanessa Mawer. (2017). Events Project Management. London: Routledge. Google Scholar

Herdiana. (2019). Peran Masyarakat dalam Pengembangan Desa Wisata Berbasis Masyarakat. Jurnal Master Pariwisata. Google Scholar

Hermawan, H. (2017). Mengenal Paritisipasi Masyarakat dalam Pengembangan Pariwisata. Jurnal Pariwisata.

Hyeong Kim, J. (2014). Memory Retrieval of Cultural Event Experiences: Examining Internal and External Influences. Journal of Travel Research. Google Scholar

Lorio, M. (2013). Community-based tourism and networking: Viscri, Romania. Journal of Sustainable Tourism. Google Scholar

Noor, A. (2017). Managemen Event. Bandung: Alfabeta.

Salvador, A. (2015). Cultural Event Recognition With Visual ConvNets and Temporal Models. Proceedings of the IEEE Conference on Computer Vision and Pattern Recognition (CVPR) Workshops. Google Scholar 
W., C. (2018). Peranan Masyarakat Lokal dalam Pengembangan Cultural Tourism. Jurnal Tourism and Hospitality.Akhoondnejad, A. (2016). Tourist Loyalty to A Local Cultural Event: The Case Of Turkmen Handicrafts Festival. Tourism Management.

Copyright holder:

Ahmad Kurniawan, Elly Malihah, Rini Andari (2022)

First publication right:

Syntax Idea

This article is licensed under:

(c) (†) (?) 